\title{
European framework to decrease the burden of TB/HIV
}

\author{
P. de Colombani, N. Banatvala, R. Zaleskis, D. Maher, on behalf of the WHO regional office for Europe*
}

European framework to decrease the burden of TB/HIV. P. de Colombani, $N$. Banatvala, $R$. Zaleskis, D. Maher, on behalf of the WHO regional office for Europe. ABSTRACT: Tuberculosis (TB) in Europe is declining in countries in western and central Europe, but the burden is still high and increasing in eastern Europe. HIVIAIDS is increasing dramatically in eastern Europe. HIV-related tuberculosis (TB/HIV) morbidity and mortality are expected to accelerate significantly in the future.

This framework aims to guide European countries in developing their national plan for reducing TB/HIV morbidity and mortality. It results from an extensive consultation process undertaken by the World Health Organization Regional Office for Europe and by those responsible for HIVIAIDS and TB programmes and their partners. It builds on strategies developed globally and in Europe for TB control and for HIVIAIDS prevention and care.

This framework sets out the rationale for effective collaboration between HIVIAIDS and tuberculosis national programmes. It identifies five strategic components (political commitment, collaborative prevention, intensified case-finding, coordinated treatment and strengthened surveillance) and eight key operations (central coordination, policy development, surveillance, training, supply management, service delivery, health promotion and research).

Eur Respir J 2004; 24: 493-501.
Correspondence: WHO Regional Office for Europe, Scherfigsvej 8, DK-2100 Copenhagen $\varnothing$, Denmark.

\section{Keywords: AIDS}

delivery of healthcare

Europe

health policy

HIV infections

tuberculosis

Received: June 22004

Accepted: June 22004

*Reproduction of the WHO publication: "European framework to decrease the burden of TB/HIV" WHO/Eur/03/5037600; ISBN 92 8901089 4. The copyright for this article belongs to the World Health Organization.
The World Health Organization (WHO) declared tuberculosis (TB) to be a global emergency in 1993 [1] and formulated the DOTS strategy to control TB in 1994 [2]. More recently, WHO published an expanded framework (Appendix 1) for effective TB control that covers the technical, managerial, social and political dimensions [3]. By 2002, 155 countries were implementing the DOTS strategy [4]. However, only $33 \%$ of global TB cases were reported to be covered by DOTS in 2001, with considerable variation between regions. The European Region of WHO reported 13\% DOTS population coverage, the lowest among the WHO regions.

In 2001, the United Nations declared HIV/AIDS to be a global emergency of devastating impact. Member States committed themselves with the Declaration of Commitment on HIV/AIDS of the United Nations General Assembly Special Session (UNGASS) on HIV/AIDS [5] to address the HIV/AIDS crisis urgently. Priority has been given to ensuring access to care and support for the people living with HIV/ AIDS (PLWHA) and to scaling up antiretroviral (ARV) therapy to reach 3 million PLWHA by 2005 [6].

TB and HIV/AIDS are global public health problems with considerable mutual interaction. Globally, TB is a leading killer of PLWHA. HIV is the most potent force driving the TB epidemic in countries with a high prevalence of HIV. Given the close interaction between the TB and HIV epidemics, the global Stop TB Partnership established the TB/HIV Working Group in 2001 to coordinate and promote interventions to decrease the burden of HIV-related TB (TB/ HIV). The Working Group developed a global TB/HIV strategic framework [7] and supportive guidelines for implementation [8] that need to be adapted in each WHO region.

TB in Europe is declining in countries in western and central Europe (including Albania, Bosnia and Herzegovina, Bulgaria, Croatia, Czech Republic, Hungary, Poland, Romania, Serbia and Montenegro, Slovakia, Slovenia, The Former Yugoslav Republic of Macedonia and Turkey, for central Europe), but the burden is still high and increasing in eastern Europe (including Armenia, Azerbaijan, Belarus, Estonia, Georgia, Kazakhstan, Kyrgyzstan, Latvia, Lithuania, Republic of Moldova, Russian Federation, Tajikistan, Turkmenistan, Ukraine and Uzbekistan) [9]. HIV/AIDS, which has been prevalent in the past in countries in western Europe, is increasing dramatically in eastern Europe. TB/HIV morbidity and mortality in Europe are expected to accelerate significantly.

In 2002, the WHO Regional Committee for Europe urged Member States to develop comprehensive, multisectoral, national HIV/AIDS strategic plans and programmes [10], and to promote effective collaboration between programmes to prevent and control TB and HIV [11]. This framework results from the renewed commitment against TB and HIV/ AIDS in Europe. It results from an extensive consultation process, including the Wolfheze Workshops on Tuberculosis Control in Europe (2001-2003) undertaken by the WHO Regional Office for Europe and by those responsible for national HIV/AIDS and TB programmes and their partners.

This framework aims to guide European countries in developing their national plan for reducing TB/HIV morbidity and mortality. It builds on strategies developed globally and in Europe for TB control [3, 12, 13] and for HIV/AIDS prevention and care [14]. It sets out the rationale for effective action to address TB/HIV, including the collaboration between national HIV/AIDS programmes and national TB programmes. It identifies the populations at risk of TB and HIV, and the strategic components and key operations required. The main target audience consists of policymakers in ministries (especially ministries responsible for health, justice and the interior), international agencies and nongovernmental organisations (NGOs). 
WHO will revise this framework in the future as further evidence becomes available to inform policy and practice related to TB/HIV. Response to the current article to the WHO Regional Office for Europe with views and comments is kindly invited.

\section{Background}

\section{Links between $T B$ and HIV}

HIV can fuel the TB epidemic in several ways $[15,16]$. HIV is the most potent known risk factor for progression to active TB in people with latent Mycobacterium tuberculosis infection. HIV also increases the rate of recurrent $\mathrm{TB}$, either from endogenous reactivation or exogenous reinfection. Increasing $\mathrm{TB}$ cases among PLWHA enhances the risk of TB transmission to the general community, whether or not they are HIV infected. The level of immunodeficiency at which PLWHA usually develop TB is associated with higher case-fatality rates.

TB may adversely affect the natural history of AIDS in coinfected people, by stimulating HIV replication directly by M. tuberculosis and its cellular components and/or indirectly by releasing cytokines [17, 18]. However, evidence for this is mainly based on studies in vitro [19] and is not yet conclusive in epidemiological studies.

\section{Epidemiology}

WHO estimated that there were 484,000 new TB cases in Europe in 2001, representing $6 \%$ of the global TB burden. The Russian Federation had the ninth highest burden of TB in the world. Within Europe, the TB incidence varies enormously, from 5 per 100,000 population in Sweden to 181 per 100,000 population in Kazakhstan [4]. The female/male ratio was 0.4 among new pulmonary TB cases with a positive sputum smear. This may require research on sex inequality in accessing TB services in some settings [20]. High rates of TB are associated with socioeconomic crisis, weaknesses in health systems, epidemics of HIV and multidrug-resistant TB, and poor interventions to control TB among vulnerable populations [21]. Recent analysis shows that $2.6 \%$ of all new TB cases in Europe in 2000 were attributable to HIV co-infection [22]. In the Russian Federation, $1 \%$ of all new cases of TB were estimated to be HIVpositive and $35 \%$ of the adults with AIDS have died from TB.

The Joint United Nations Programme on HIV/AIDS (UNAIDS) and WHO estimate that Europe had $\sim 1.77$ million PLWHA in 2001: 4\% of the global HIV/AIDS burden [23, 24]. The HIV/AIDS epidemic in Europe is the fastest growing in the world. In countries in eastern and central Europe, the HIV epidemic is mostly concentrated among specific high-risk groups, mainly injecting drug users (IDUs). Their numbers are rising dramatically in eastern European countries because of global drug trafficking, unemployment and poverty. In western Europe, the HIV epidemic started in the 1970s and 1980s and has reached a $0.3 \%$ prevalence in adults, mainly being transmitted by males who have sex with other males and IDUs. HIV surveillance needs to be strengthened further to better monitor the scale of the HIV epidemic and trends in Europe.

\section{Aim, guiding principles and targets}

\section{Aim}

The aim of the current framework is to assist European countries in planning and implementing TB/HIV interventions jointly by national HIV/AIDS programmes and national TB programmes, with the objective of reducing HIV-related TB morbidity and mortality and minimising the effects on individual people and on societies.

\section{Guiding principles}

This framework is based on the following guiding principles. 1) Controlling $\mathrm{TB} / \mathrm{HIV}$ requires implementing a range of interventions, including those directly against TB and those directly against HIV (and therefore indirectly against TB). 2) National HIV/AIDS programmes and national TB programmes should receive the necessary support to fully implement their respective strategies for preventing HIV/ AIDS and providing care and support, and for controlling TB according to internationally recommended standards. 3) National HIV/AIDS programmes and national TB programmes should collaborate to ensure that people with HIV/ AIDS and people with TB receive a continuum of high-quality care. 4) Access to TB/HIV services is a human right; it should be protected by confidentiality, should be equitable and should exclude discrimination, including that based on stigma or sex.

\section{Targets}

There are internationally agreed global targets for TB and for HIV but not yet specifically for HIV-related TB. The World Health Assembly passed a resolution in 2000 urging that $\geqslant 70 \%$ of all new infectious TB cases be detected and that $\geqslant 85 \%$ of those detected be cured by 2005 [25]. The Millennium Development Goals adopted at the Millennium Summit in September 2000 include the following targets: "to have halted by 2015 and begun to reverse the spread of HIV" and "to have halted by 2015 and begun to reverse the incidence of TB" [26]. The TB/HIV Working Group is presently working to define global and regional targets for TB/HIV and monitoring indicators.

\section{Priorities for TB/HIV in Europe}

\section{Setting priorities among countries}

Countries in Europe face diverse challenges in responding to TB/HIV. The 52 countries vary considerably in the epidemiological burdens of HIV and TB, and the type and quantities of new activities needed to provide the internationally recommended TB and HIV/AIDS services. A country with a high case load, an increasing epidemiological trend and inadequate resources and/ or inadequate health system represents a priority for intervention.

Using the above criteria, the sexually transmitted infections (STI)/HIV/AIDS programme and the TB control programme of the WHO Regional Office for Europe have set priorities among European countries, according to the need for HIV/ AIDS prevention and control [27] and TB control [28] in the next 5 yrs. Table 1 further groups countries with a combined perspective for priority intervention. The countries with high needs for both HIV/AIDS prevention and control and TB control are also those with the highest need to address TB/HIV.

\section{Populations at high risk of $H I V$ and $T B$}

IDUs are at risk of HIV infection, TB and, in some settings, multidrug-resistant TB. More than two thirds of newly diagnosed HIV infections in eastern Europe are among 
Table 1.-Countries in the European Region according to priority for the need to prevent and control HIV/AIDS and to control tuberculosis (TB)

\begin{tabular}{|c|c|c|c|}
\hline & \multicolumn{3}{|c|}{ Priority for HIV/AIDS prevention and control } \\
\hline & Low & Intermediate & High \\
\hline \multicolumn{4}{|c|}{ Priority for TB control } \\
\hline Low & $\begin{array}{l}\text { Andorra, Austria, Belgium, } \\
\text { Czech Republic, Cyprus, } \\
\text { Denmark, Finland, Germany, } \\
\text { Greece, Iceland, Ireland, Israel, } \\
\text { Luxembourg, Malta, Monaco, } \\
\text { Netherlands, Norway, } \\
\text { San Marino, Slovakia, } \\
\text { Slovenia, Sweden, Switzerland }\end{array}$ & Italy, France, UK & \\
\hline Intermediate & $\begin{array}{l}\text { Albania, Bosnia and Herzegovina, } \\
\text { Bulgaria, Croatia, Hungary, } \\
\text { Serbia and Montenegro, The former } \\
\text { Yugoslav Republic of Macedonia }\end{array}$ & Poland, Portugal, Spain, Turkey & \\
\hline High & Turkmenistan & $\begin{array}{l}\text { Armenia, Azerbaijan, Georgia, } \\
\text { Kazakhstan, Kyrgyzstan, } \\
\text { Romania, Tajikistan, Uzbekistan }\end{array}$ & $\begin{array}{l}\text { Belarus, Estonia, } \\
\text { Latvia, Lithuania, } \\
\text { Republic of Moldova, } \\
\text { Russian Federation, } \\
\text { Ukraine }\end{array}$ \\
\hline
\end{tabular}

IDUs [29]. An estimated $\geqslant 1 \%$ of the population in eastern Europe (excluding Estonia, Latvia and Lithuania) are IDUs and half are aged $<25$ yrs. Sexual partners of IDUs are at risk of HIV. IDUs often engage in sex work to support their injecting habit, which increases the risk of HIV transmission to the general population.

Sex workers (SWs) are at higher risk of HIV because of behaviour such as unsafe sex and unsafe injecting drug-use practices. SWs may represent a significant channel of HIV transmission to the general population.

Prisoners are at high-risk of TB, especially in crowded facilities. Moreover, prisoners often come from populations at high risk of HIV [30] because of the illicit nature of drug use and sex work and the high rates of property crime to support drug use by IDUs. The risk of TB infection and disease is consistently higher among prison inmates than among the general population, and this increases with the length of detention. Special issues for controlling TB among prisoners include: the rapid progression of clinical TB among HIV-positive prisoners; the spread of TB to other prisoners and prison staff; the spread of TB to the community at large when prisoners need hospital care or are released; and the additional costs of isolating, investigating and treating cases [31, 32].

Migrant populations account officially for $2.7 \%$ of the European population or $\sim 1 \%$ considering only those from countries outside Europe [33]. Both European and nonEuropean migrants contribute to the TB [9, 34] and HIV epidemics. Difficulties in communication, accessing healthcare services, sex barriers and the often uncertain legal status of migrants pose particular problems for TB control and HIV prevention and care in this group.

Healthcare users and health workers often have greater risk of being exposed to M. tuberculosis [35]. TB is most likely to be nosocomially transmitted from people with unrecognised pulmonary TB who have not started any anti-TB treatment and have not been isolated [36]. The emergence of multidrugresistant $\mathrm{TB}$, often combined with HIV infection, confronts the healthcare community with unique challenges. Nosocomial TB transmission among HIV-infected patients in Europe has caused outbreaks with high case-fatality rates. HIVinfected people have a high attack rate and a shortened incubation period for TB and are susceptible to re-infection, including re-infection with drug-resistant strains.

\section{Strategic components}

The strategic framework to reduce the burden of TB/HIV in Europe is based on the collaboration of national HIV/AIDS programmes and national TB programmes in promoting five components: political commitment, collaborative prevention, intensified case-finding, coordinated treatment and strengthened surveillance. The collaboration of national HIV/AIDS programmes and national TB programmes is based on the guiding principles outlined in the Aim, guiding principles and targets section.

\section{Political commitment}

Political commitment is needed to promote full implementation of the strategies for HIV/AIDS prevention and control, for TB control and for the programmes' collaborative efforts to tackle TB/HIV. Establishing a national high-level committee may promote coordination, intrasectoral and intersectoral collaboration, and additional political and financial support. Existing international initiatives should be utilised to foster government commitment and provide additional resources, such as the Stop TB Partnership and the Global Fund to Fight AIDS, Tuberculosis and Malaria.

\section{Collaborative prevention for $T B$ and HIV transmission}

The core responsibilities of the national HIV/AIDS programme for HIV/AIDS prevention include promoting safer sex and safer injecting drug use, treating STI, screening blood for HIV, implementing universal precautions, providing prophylaxis to prevent mother-to-child transmission of HIV, and diagnosing HIV infection early. All of these interventions can reduce HIV transmission, thereby contributing to a declining burden of TB/HIV. The core responsibility of the national $\mathrm{TB}$ programme is to fully implement the international strategy for controlling TB. Three specific preventive interventions are recommended for collaborative action by national HIV/AIDS programmes and national TB programmes: isoniazid preventive therapy (IPT), environmental measures and postexposure prophylaxis (PEP).

IPT should be administered to PLWHA with a positive 
tuberculin skin test. This decreases the risk that recent M. tuberculosis infection progresses and that latent infection is reactivated [37, 38]. Two important requirements are to exclude active TB and to ensure adherence to treatment [39]. The widely used 6-month course is based on a costeffectiveness study $[40,41]$. Extending to 9 months might be considered to maximise the efficacy of IPT, depending on local conditions [42, 43]. Further evidence is necessary to guide IPT where isoniazid resistance is common [43].

Healthcare users and workers are exposed to a higher risk of TB and HIV transmission in healthcare facilities; this also applies to other settings, such as prisons. Environmental measures can reduce TB transmission with minimal additional resources [35]. These include separating or isolating infectious people (following early TB diagnosis and treatment), room ventilation, face masks for patients, laboratory safety and waste disposal. Universal precautions should be also applied in HIV/AIDS and TB settings [44].

Occupational exposure to blood or other fluids that may contain HIV should be considered an urgent health concern in all settings, including TB facilities. HIV PEP should be available for prompt administration in accordance with current recommendations [45].

\section{Intensified case-finding}

Intensified case-finding of HIV among people with TB and of TB among PLWHA should be intensified, especially among the high-risk groups mentioned in the previous section. Early diagnosis of both conditions can limit transmission, decrease the related morbidity and mortality, and improve people's quality of life. Voluntary counselling and testing (VCT) is an important entry point for providing comprehensive care to PLWHA. This also includes ARV therapy among TB patients and TB screening among PLWHA, followed by treatment or IPT [46]. Investigation of PLWHA with respiratory symptoms consistent with TB should always include sputum-smear microscopy (and culture for M. tuberculosis where available).

\section{Coordinated treatment}

Coordinated treatment of PLWHA who have TB with antiTB drugs and ARV drugs requires careful clinical management. TB treatment should usually have priority over ARV therapy. It should contain rifampicin and be initiated promptly and directly observed. Careful evaluation is necessary in judging when to start ARV therapy because of the potential interaction of ARV drugs with rifampicin and the risk of a paradoxical reaction (due to immune reconstitution syndrome). In patients with pulmonary TB and CD4 T-lymphocyte count $>200$ per $\mathrm{mm}^{3}$, ARV therapy should be deferred until TB treatment is completed. In patients with a high risk of HIV disease progression and mortality (extrapulmonary TB or CD4 count $<200$ per $\mathrm{mm}^{3}$ ), ARV therapy should be provided concurrently with TB treatment. Recent publications advise further on treating PLWHA who have TB $[47,48]$. Intensive support to promote adherence to ARV therapy may include directly observed treatment (DOT).

\section{Strengthened surveillance}

Strengthened surveillance is critical in controlling TB [49, 50] and HIV/AIDS [51, 52]. Effective surveillance provides data that can be used to develop evidence-based policy, monitor programmes and evaluate impact. An effective surveillance system should be able to identify the number and proportion of PLWHA who have TB, the number and proportion of TB patients who are HIV-positive, the risk factors associated with TB/HIV infection, the sex differences, the modalities and outcome of care [53, 54], and the level of drug resistance [55]. Surveillance systems for TB and HIV/ AIDS should be sufficiently integrated to be able to perform these functions. Effective methods of linking data on TB and HIV/AIDS must preserve people's right to confidentiality [56]. Notification of HIV together with notification of the same person for other diseases should maintain confidentiality.

\section{Key operations}

To successfully promote the five strategic components in tackling TB/HIV, the national HIV/AIDS programmes and national TB programmes should jointly ensure eight key operations: central coordination, policy development, surveillance, training, supply management, service delivery, health promotion and research. Each country should determine the most effective way of implementing these key operations, depending on the burden of TB/HIV, the organisation of the health system and the availability of resources. The full involvement and participation of PLWHA and of TB patients in designing, planning, implementing and evaluating TB/HIV interventions is crucial.

\section{Central coordination}

Central coordination through a national TB/HIV coordinating committee enables national HIV/AIDS programmes and national TB programmes to jointly plan, implement, monitor and evaluate TB/HIV interventions. The committee should include managers from central and peripheral levels of relevant ministries, such as those responsible for health, the interior and justice, and civil society representatives, such as those from patients' organisations, other NGOs and the private sector.

\section{Policy development}

Policy development supports the effective coordination of and collaboration on TB/HIV interventions. The main areas of work include: 1) developing policies that promote closer collaboration between national HIV/AIDS programmes and national TB programmes; 2) reviewing the guidelines of national HIV/AIDS programmes and national TB programmes to ensure that they include TB/HIV; 3) developing national protocols and standards for good clinical practice, including ethics and confidentiality; 4) developing partnership with stakeholders, including NGOs, such as patients' organisations and charitable organisations, and private enterprises; and 5) establishing referral systems between the services of national HIV/AIDS programmes and national TB programmes. An advisory group should develop national TB/HIV policies and guidelines. Such a group should include epidemiologists, public health officials, and representatives of the ministry of health, other relevant ministries, NGOs and other partners, such as specialised HIV/AIDS and drug control agencies.

\section{Surveillance}

Surveillance is critical for monitoring progress in implementing $\mathrm{TB} / \mathrm{HIV}$ interventions, such as using population-based 
outcome measures, and evaluating progress towards achieving targets. Appendix 2 lists specific TB/HIV indicators that national HIV/AIDS programmes and national TB programmes can use, which may require revising forms and registers to collect data. The national HIV/AIDS programmes and national TB programmes should collaborate in sharing data whilst preserving patient confidentiality. Patient referral should be properly documented. Collecting and analysing data by sex and age helps to clarify the magnitude and nature of sex disparities and to inform prevention and care programmes. National and regional surveillance reports on HIV/AIDS should include TB as a priority HIV-related disease, and reports on TB should include HIV as an important factor that fuels TB.

\section{Training}

Training on the job should be planned for personnel and other service providers, such as volunteers, to increase and update knowledge on the transmission, prevention and care of HIV/AIDS, TB and TB/HIV. It should also cover universal precautions against HIV and preventing $\mathrm{HIV}$ and TB transmission in special settings, such as hospitals, drug dependence treatment services and prisons. Training on how to communicate effectively with patients is also important, especially considering barriers resulting from stigma and social differences. Collaboration between universities, training institutions, professional societies and NGOs is important in developing graduate and postgraduate education and training for health staff involved in HIV/AIDS and TB programmes.

\section{Supply management}

Supply management is essential to ensure an uninterrupted supply of high-quality anti-TB drugs. This enables TB patients to receive an uninterrupted course of effective treatment and reduces the risk of drug resistance. The same applies to effective IPT. When PLWHA are screened for TB by non-TB services, this should be supported by at least adequate supplies for collecting sputum smears and shipping the samples. Supply management is also a key issue for national HIV/AIDS programmes in scaling up ARV therapy to reach the target of 3 million PLWHA by 2005. The availability of ARV drugs may promote uptake of VCT. The national HIV/AIDS programmes and national TB programmes need to collaborate in providing PLWHA who have TB with ARV therapy, whether in TB or in infectious disease or HIV facilities. The Global TB Drug Facility provides a good model for procuring, controlling the quality of and distributing ARV drugs.

\section{Service delivery}

Service delivery involves clarifying the professional and administrative responsibilities necessary to provide six priority collaborative services between the national TB programmes and national HIV/AIDS programmes (Appendix 3): 1) making available VCT for all TB patients; 2) referring TB patients who are found to be HIV-positive for lifelong HIV support, care and treatment; 3) detecting and treating TB among PLWHA; 4) ensuring IPT treatment to PLWHA who are infected with TB, but found not to have active TB; 5) applying universal HIV precautions and environmental TB measures for healthcare workers and users; and 6) making available PEP for everyone exposed to HIV.

These collaborative services are part of an HIV/AIDS essential package that includes interventions against HIV (and therefore indirectly against TB) and interventions directly against TB. Services can be delivered at home and at the primary, secondary and tertiary levels of care. Service delivery in each country should be planned based on the epidemiology of $\mathrm{TB} / \mathrm{HIV}$, the organisation of the health system and the resources available. NGOs may be key partners in serving populations at high risk of HIV and TB. As many PLWHA are IDUs, drug dependence treatment services should be also considered for delivering TB/HIV services. Services at the community level include community support for PLWHA and for TB patients to ensure that they adhere to treatment. Primary care services include VCT, IPT and TB treatment. The national HIV/AIDS programmes and national TB programmes should collaborate in exploring the possibility of jointly organising DOT for anti-TB treatment and introducing ARV therapy. Universal HIV precautions and environmental TB measures should be also considered from primary care level. Secondary care services include diagnosing and treating common HIV-related diseases, including pulmonary and extrapulmonary TB (diagnosis usually requires such investigations as smear microscopy, radiography, biopsy and culture). PEP against HIV infection should also be available in secondary healthcare facilities. Tertiary care services should include diagnosing and treating the complications of HIV-related diseases. Managing HIV/AIDS and TB patients requires a systematic, effective referral system between HIV and TB services and providing services sensitive to social, sex and cultural differences at all levels.

\section{Health promotion}

Health promotion through advocacy, communication and social mobilisation is essential for expanding the HIV/AIDS and DOTS strategies. Combining the resources and experiences of national HIV/AIDS programmes and national TB programmes could enhance advocacy, communication and social mobilisation. Reaching larger audiences is likely to increase political and financial support. More effective means and tools for social mobilisation can be accessed and collaboration expanded to a larger number of partners, such as NGOs and the private sector, for communities demanding effective prevention, treatment and care of HIV/AIDS, TB and TB/HIV.

\section{Research}

Research is essential in all public health programmes. National HIV/AIDS programmes and national tuberculosis programmes have considerable unexploited potential synergy for HIV-related tuberculosis intervention. Epidemiological research and surveillance should inform the priorities set among interventions and monitor their impact. Clinical research may improve the diagnosis, treatment and prophylaxis of HIV-related tuberculosis. Operational research is relevant to improving intensified tuberculosis case-finding, managing HIV-related tuberculosis patients, supply, training, and intrasectoral and intersectoral collaboration. Assessing the feasibility, effectiveness, affordability and cost-effectiveness of antiretroviral therapy and isoniazid preventive therapy in central and eastern Europe is a priority [28]. Where isoniazid resistance is common, research is needed to determine the 
appropriate preventive treatment regimen for tuberculosis. Research can help to explore the possible effects of sex inequality in accessing tuberculosis services [57].

\section{Appendix 1: Main definitions}

Countries in Europe with a low TB incidence: European countries with an annual notified incidence rate of $<20$ cases (all types of TB) per 100,000 population.

Directly observed treatment (DOT): A trained and supervised person observes the person swallowing the drugs. This is part of a range of measures to support people with TB and promote adherence to treatment.

The DOTS strategy: The recommended strategy for TB control that is expanded to apply to both HIV-related and drug-resistant forms of TB. It includes five elements: 1) sustained political commitment to increase human and financial resources and make TB control a nationwide activity integral to a national health system; 2) access to qualityassured sputum microscopy for detecting cases of TB among people presenting with, or found through screening to have, symptoms of TB (most importantly, prolonged cough), with special attention to detecting cases among HIV-infected people and other high-risk groups, such as people living in institutions; 3) standardised short-course chemotherapy for all cases of TB under proper casemanagement conditions through technically sound and socially supportive treatment services, including direct observation of treatment; 4) an uninterrupted supply of qualityassured drugs with reliable systems of drug procurement and distribution; and 5) a recording and reporting system enabling outcome assessment of each and every patient and assessment of the overall performance of the programme.

Elimination of TB: Annual incidence of sputum smearpositive TB $<1$ case per million population or prevalence of infection with $M$. tuberculosis $<1 \%$ and declining.

Harm reduction: Policies or programmes that focus on reducing the harm resulting from the use of drugs [58]. The term is used especially for policies and programmes that aim to reduce harm without necessarily affecting the underlying drug use and requiring abstention from drug use. Examples include needle and syringe exchange and distribution programmes to counteract needle-sharing among IDUs and treatment of sexually transmitted infections among IDUs. However, harm reduction approaches are often the first step towards the eventual cessation of drug use.

Highly active antiretroviral therapy: Treatment based on multiple drugs, including a combination of protease inhibitors, nucleoside reverse transcriptase inhibitors and nonnucleoside reverse transcriptase inhibitors.

HIV epidemic levels: 1) low level: HIV prevalence has not consistently exceeded 5\% in any defined subpopulation; 2) concentrated: HIV prevalence consistently $>5 \%$ in at least one defined subpopulation but $<1 \%$ in pregnant women in urban areas; 3) generalised: HIV prevalence consistently $>1 \%$ in pregnant women.

Population at high risk of TB: Population with an annual notification rate of $\geqslant 100$ cases (any type of TB) per 100,000 population.

Voluntary counselling and testing (VCT): Services providing pretest counselling, testing for HIV infection and post-test counselling for anyone wanting to know their HIV status.

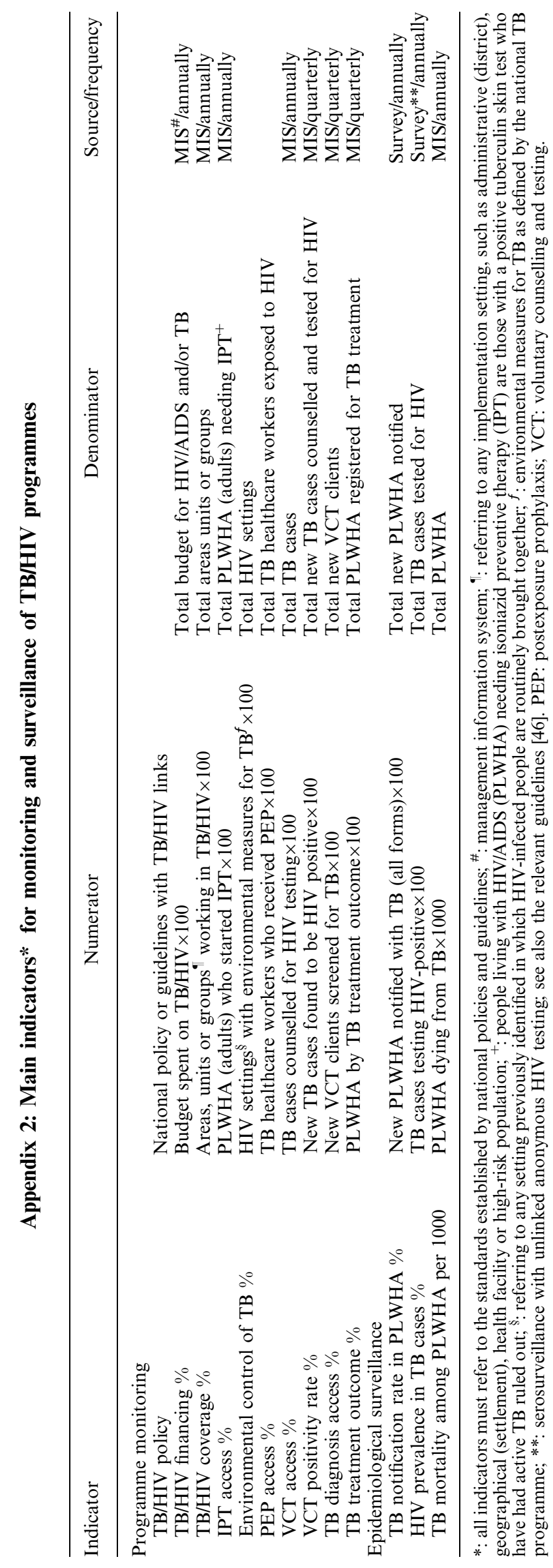




\section{Appendix 3: Essential package of HIVIAIDS and TB interventions}

The four tables below list the essential package of HIV/ AIDS interventions and TB interventions that healthcare systems should provide [8]. They are against HIV (and therefore indirectly against TB) and directly against TB.

\section{Preventing transmission}

Interventions directly targeting $\mathrm{HIV}^{*}$ Interventions directly (and therefore indirectly $\mathrm{TB}$ ) targeting $\mathrm{TB}$

Safer drug use

Harm reduction

Substitution therapy

Safer sex

Condom promotion

Reducing the number of sexual partners

Voluntary counselling and testing

Prevention and treatment of sexually transmitted infections

Prevention of mother-to-child transmission

Antiretroviral therapy

Diagnosing and treating infectious cases ${ }^{\#}$

Safe blood

Universal precautions

Environmental measures ${ }^{\#}$

Diagnosing early stages of infection or disease

Interventions directly targeting $\mathrm{HIV}^{*} \quad$ Interventions directly (and therefore indirectly TB)

targeting TB

\begin{tabular}{cc}
\hline Voluntary counselling and testing $^{\#}$ & $\begin{array}{c}\text { Sputum smear } \\
\text { microscopy } \\
\text { Intensified case-finding }\end{array}$ \\
\hline
\end{tabular}

Preventing progression from infection to disease

Interventions directly targeting $\mathrm{HIV}^{*} \quad$ Interventions directly (and therefore indirectly TB) targeting TB

\begin{tabular}{lc}
\hline Antiretroviral therapy & $\begin{array}{c}\text { Isoniazid preventive } \\
\text { therapy }\end{array}$ \\
Postexposure prophylaxis &
\end{tabular}

\section{Treatment and care}

Interventions directly targeting $\mathrm{HIV}^{*}$ (and therefore indirectly TB)

Interventions directly targeting $\mathrm{TB}$

Antiretroviral therapy

Cotrimoxazole prophylaxis

Prevention of fungal infection

Treatment of common infections (pneumonia, diarrhoea and Candida Albicans)

Treatment of tumours (Kaposi's sarcoma and lymphoma)

Nutritional supplementation

Treatment of less common infections

Treatment of complications (including TB) ${ }^{\#}$

Palliative care

*: these may target high-risk behaviour, environments or communities;

\#: these services require collaboration between national HIV/AIDS programmes and national TB programmes.
All rights reserved. The Regional Office for Europe of the World Health Organization welcomes requests for permission to reproduce or translate its publications, in part or in full.

The designations employed and the presentation of the material in this publication do not imply the expression of any opinion whatsoever on the part of the World Health Organization concerning the legal status of any country, territory, city or area or of its authorities, or concerning the delimitation of its frontiers or boundaries. Where the designation "country or area" appears in the headings of tables, it covers countries, territories, cities, or areas. Dotted lines on maps represent approximate border lines for which there may not yet be full agreement.

The mention of specific companies or of certain manufacturers' products does not imply that they are endorsed or recommended by the World Health Organization in preference to others of a similar nature that are not mentioned. Errors and omissions excepted, the names of proprietary products are distinguished by initial capital letters.

The World Health Organization does not warrant that the information contained in this publication is complete and correct and shall not be liable for any damages incurred as a result of its use. The views expressed by authors or editors do not necessarily represent the decisions or the stated policy of the World Health Organization.

This document was prepared by: $\mathrm{P}$. de Colombani (WHO Regional Office for Europe, Copenhagen, Denmark), N. Banatvala (Dept for International Development, London, UK), R. Zaleskis (WHO Regional Office for Europe, Copenhagen, Denmark) and D. Maher (WHO headquarters, Geneva, Switzerland).

The document was reviewed by a Review Panel composed of: $\mathrm{T}$. Aleksandrina (National Tuberculosis Programme, Kiev, Ukraine), A. Ball (WHO headquarters, Geneva, Switzerland), D. Erzen (National Tuberculosis Programme, Golnik, Slovenia), D. Farge-Bancel (Saint-Louis Hospital, Paris, France), P. Godfrey-Faussett (London School of Hygiene and Tropical Medicine, UK), A. Infuso (Surveillance of Tuberculosis in Europe, EuroTB, Saint-Maurice, France), S. Matic (WHO Regional Office for Europe, Copenhagen, Denmark), G.B. Migliori (Fondazione S. Maugeri, Tradate, Italy), M. Bijl (AIDS Foundation EastWest, Moscow, Russian Federation), H. Rieder (International Union against Tuberculosis and Lung Disease, Paris, France), T. Shoumilina (UNAIDS, Moscow, Russian Federation), J. Veen (KNCV, The Hague, the Netherlands) and I. Yordi Aguirre (WHO Regional Office for Europe, Copenhagen, Denmark).

Eramova, B. Hauer, J. Leese, P. Van Maaren, E. Pontali, P. Ramon-Pardo, A. Reid, J. Scholten and A. Thorson provided valuable contributions to this document.

\section{References}

1. World Health Assembly. Tuberculosis programme. Geneva, World Health Organization, 1993 (WHA46.36).

2. Framework for effective tuberculosis control. WHO/TB/94.179 Geneva, World Health Organization (1994). whqlibdoc. who.int/hq/1994/WHO_TB_94.179.pdf. Date accessed: 25 September 2003.

3. An expanded DOTS framework for effective tuberculosis control. WHO/CDS/TB/2002.297 Geneva, World Health 
Organization (2002). www.who.int/gtb/dots/2002-297.htm. Date accessed: 25 September 2003.

4. Global tuberculosis control: surveillance, planning, financing. WHO/CDS/TB/2003.316 Geneva, World Health Organization (2003). www.who.int/gtb/publications/globrep/ contents.html. Date accessed: 25 September 2003.

5. United Nations General Assembly. Declaration of commitment on HIV/AIDS. Resolution adopted by the General Assembly, 26th Special Session. New York, United Nations (2001). www.un.org/ga/aids/coverage/FinalDeclarationHIVAIDS. html. Date accessed: 25 September 2003.

6. 3 million HIV/AIDS sufferers could receive anti-retroviral therapy by 2005. New hope for those in developing world. Geneva, World Health Organization (2002). www.who.int/ mediacentre/releases/who58/en. Date accessed: 25 September 2003.

7. Maher D, Floyd K, Raviglione M. A strategic framework to decrease the burden of TB/HIV. WHO/CDS/TB/2002.296 and WHO/HIV_AIDS/2002.2 Geneva, World Health Organization (2002). www.who.int/gtb/publications/tb_hiv/2002_296. Date accessed: 25 September 2003.

8. Guidelines for implementing collaborative $\mathrm{TB}$ and $\mathrm{HIV}$ programme activities. WHO/CDS/TB/2003.319 and WHO/ HIV/2003.01 Geneva, World Health Organization (2003). www.who.int/hiv/pub/prev_care/pub31/en. Date accessed: 25 September 2003.

9. Surveillance of Tuberculosis in Europe - EuroTB (InVS/ $\mathrm{KNCV}$ ) and the national coordinators for tuberculosis surveillance in the WHO European Region. Report on tuberculosis cases notified in 2000. Saint-Maurice, Institut de Veille Sanitaire (2003). www.eurotb.org/rapports/ 2000/ rapport_eurotb_2000.htm. Date accessed: 25 September 2003.

10. WHO Regional Committee for Europe. Scaling-up the response to HIV/AIDS in the European Region of WHO (EUR/RC52/R9). Copenhagen, WHO Regional Office for Europe, 2002.

11. WHO Regional Committee for Europe. Scaling-up the response to tuberculosis in the European Region of WHO (EUR/RC52/R8). Copenhagen, WHO Regional Office for Europe, 2002.

12. Broekmans JF, Migliori GB, Rieder HL, et al. European framework for tuberculosis control and elimination in countries with a low incidence. Eur Respir J 2002; 19: 765-775.

13. Strategy to control tuberculosis in the WHO European Region. Copenhagen, WHO Regional Office for Europe, 2000.

14. Global Health-Sector Strategy for HIV/AIDS, 2003-2007. Providing a framework for partnership and action. HIV/2002.25 Geneva, World Health Organization (2003). www.who.int/hiv/pub/advocacy/ghss/en. Date accessed: 25 September 2003.

15. Lienhardt C, Rodriques LC. Estimation of the impact of the human immunodeficiency virus infection on tuberculosis: tuberculosis risks revised? Int J Tuberc Lung Dis 1997; 1: 196-204.

16. Girardi E, Raviglione MC, Antonucci G, Godfrey-Faussett P, Ippolito G. Impact of the HIV epidemic on the spread of other diseases: the case of tuberculosis. AIDS 2000; 14: Suppl. 3, S47-S56.

17. Nakata K, Rom WN, Honda $\mathrm{Y}$, et al. Mycobacterium tuberculosis enhances human immunodeficiency virus-1 replication in the lung. Am J Respir Crit Care Med 1997; 155: 996-1003.

18. Whalen C, Horsburgh CR, Hom D, Lahart C, Simberkoff M, Ellner J. Accelerated course of human immunodeficiency virus infection after tuberculosis. Am J Respir Crit Care Med 1995; 151: 129-135.

19. Del Amo J, Malin AS, Pozniak A, De Cock KM. Does tuberculosis accelerate the progression of HIV disease? Evidence from basic science and epidemiology. AIDS 1999; 13: $1151-1158$.

20. Shubladze N, Mdivani N, Jibuti T, Khechinashvili G. Sex and age differences among $\mathrm{TB}$ patients in Georgia. Int J Tuberc Lung Dis 2002; 6: S186.

21. Migliori GB, Centis R. Problems to control TB in eastern Europe and consequences in low incidence countries. Monaldi Arch Chest Dis 2002; 57: 285-290.

22. Corbett EL, Watt CJ, Walker N, et al. The growing burden of tuberculosis: global trends and interactions with the HIV epidemic. Arch Int Med 2003; 163: 1009-1021.

23. Report on the global HIV/AIDS epidemic. UNAIDS/02.26E Geneva, UNAIDS (2002). www.unaids.org/EN/resources/ publications/corporate+ publications/report + on + the + global+ hiv_aids+epidemic $+2002+$.asp. Date accessed: 25 September 2003.

24. AIDS epidemic update. UNAIDS/02.46E Geneva, UNAIDS (2002) www.unaids.org/Unaids/EN/Resources/Publications/ Corporate+publications/AIDS+epidemic+update+December +2002.asp. Date accessed: 25 September 2003.

25. World Health Assembly. Stop Tuberculosis Initiative. WHA 53.1 Geneva, World Health Organization, 2000.

26. Millennium Development Goals. New York, United Nations (2000) www.un.org/millenniumgoals. Date accessed: 25 September 2003.

27. Workplan for implementing a regional strategy for responding to the STI/HIV/AIDS epidemic in Europe. Copenhagen, WHO Regional Office for Europe, 2002.

28. DOTS expansion plan to stop TB in the WHO European Region, 2002-2006. Copenhagen, WHO Regional Office for Europe (2002) www.who.dk/InformationSources/Publications/Catalogue/20030109_2. Date accessed: 25 September 2003.

29. European Centre for the Epidemiological Monitoring of AIDS. HIV/AIDS surveillance in Europe. Mid-year report 2002 No. 67. Saint-Maurice, Institut de Veille Sanitaire (2002) www.eurohiv.org/AidsSurv/Rapport_67/contentsGB.htm. Date accessed: 25 September 2003.

30. Drobniewski F. Tuberculosis in prisons-forgotten plague Lancet 1995; 346: 948-949.

31. WHO guidelines on HIV infection and AIDS in prisons. WHO/GPA/DIR/93.3 Geneva, World Health Organization, (1993). whqlibdoc.who.int/hq/1993/ WHO_GPA_DIR_93.3. pdf. Date accessed: 25 September 2003.

32. Bone A, Aerts A, Grzemska M, et al. Tuberculosis control in prisons: a manual for programme managers (2000). WHO/ CDS/TB/2000.281 Geneva, World Health Organization. www.who.int/gtb/publications/prisonsNTP. Date accessed: 25 September 2003.

33. Salt J. Current trends in international migration in Europe. CDMG/2002/26 Strasbourg, Council of Europe (2002). www.coe.int/T/E/Social_Cohesion/Migration/Documentation/ Publications_and_reports $/ \mathrm{John} \% 20$ Salt's $\% 20$ report $\% 202002$ \%20english.asp\#TopOfPage. Date accessed: 25 September 2003.

34. Raviglione MC, Sudre P, Rieder HL, Spinaci S, Kochi A. Secular trends of tuberculosis in western Europe. Bull World Health Organ 1993; 71: 297-306.

35. United States Centers for Disease Control and Prevention. Guidelines for preventing the transmission of Mycobacterium tuberculosis in health-care facilities. MMWR 1994; 43: 1132.

36. Castro KG, Dooley SW, Curran JW. Transmission of HIVassociated tuberculosis to health-care workers. Lancet 1992; 340: 1043-1044.

37. Policy statement on preventive therapy against tuberculosis in people living with HIV. Report of a meeting held in Geneva 1998. WHO/TB/98.255 and UNAIDS/98.34 Geneva, World Health Organization and UNAIDS (1998) www.who.int/gtb/publications/TB_HIV_polstmnt/policy_statement.html. Date accessed: 25 September 2003.

38. Fitzgerald DW, Morse MM, Pape JW, Johnson WD. Active tuberculosis in individuals infected with human immunodeficiency virus after isoniazid prophylaxis. Clin Infect Dis 2000; 31: 1495-1497. 
39. Aisu T, Raviglione MC, van Praag E, et al. Preventive chemotherapy for HIV-associated tuberculosis in Uganda: an operational assessment at a voluntary counselling and testing centre. AIDS 1995; 9: 267-273.

40. International Union against Tuberculosis. Efficacy of various durations of isoniazid preventive therapy for tuberculosis: five years of follow-up in the IUAT trial. IUAT Committee on Prophylaxis. Bull World Health Organ 1982; 60: 555-564.

41. Snider DE, Caras GJ, Koplan JP. Preventive therapy with isoniazid. Cost-effectiveness of different durations of therapy. J Am Med Assoc 1986; 255: 1579-1583.

42. Comstock GW. How much isoniazid is needed for prevention of tuberculosis among immunocompetent adults? Int J Tuberc Lung Dis 1999; 3: 847-850.

43. American Thoracic Society. Targeted tuberculin testing and treatment of latent tuberculosis infection. Joint statement of ATS and CDC. Am J Respir Crit Care Med 2000; 161: S221S247.

44. United States Centers for Disease Control and Prevention. Perspectives in disease prevention and health promotion update: universal precautions for prevention of transmission of human immunodeficiency virus, hepatitis $\mathrm{B}$ virus, and other blood-borne pathogens in health care settings. MMWR 1998; 37: 377-388.

45. United States Centers for Disease Control and Prevention. Public health service guidelines for the management of health care workers exposures to HIV and recommendations for post-exposure prophylaxis. MMWR 1998; 47: 1-33.

46. Godfrey-Faussett P, Maher D, Mukadi YD, Nunn P, Perriens J, Raviglione M. How human immunodeficiency virus voluntary testing can contribute to tuberculosis control. Bull World Health Organ 2002; 80: 939-945.

47. Treatment of tuberculosis: guidelines for national programmes. WHO/CDS/TB/2003.313 3rd Edn. Geneva, World Health Organization (2003) www.who.int/gtb/publications/ttgnp. Date accessed: 25 September 2003.

48. Scaling up antiretroviral therapy in resource-limited settings - guidelines for a public health approach. Geneva, World Health Organization (2002). www.who.int/hiv/pub/prev_care/ pub18/en. Date accessed: 25 September 2003.

49. Clancy L, Rieder HL, Enarson DA, Spinaci S. Tuberculosis elimination in the countries of Europe and other industrialized countries. Based on a workshop held at Wolfheze, Netherlands, 4-9 March 1990, under the auspices of the
IUATLD (Europe region) and WHO. Eur Respir J 1991; 4: 1288-1295.

50. Rieder HL, Zellweger JP, Raviglione MC, Keizer ST, Migliori GB. Tuberculosis control and international migration in Europe. Eur Respir J 1994; 7: 1545-1553.

51. UNAIDS/WHO Working Group on Global HIV/AIDS and STI Surveillance. Guidelines for second generation surveillance for HIV: the next decade WHO/CDS/CSR/EDC/2000.5 and UNAIDS/00.03E. Geneva, World Health Organization and UNAIDS (2000). www.who.int/hiv/pub/epidemiology/ pub3/en. Date accessed: 25 September 2003.

52. European Centre for the Epidemiological Monitoring of AIDS. 1993 revision of the European AIDS surveillance case definition. Saint-Maurice, Institut de Veille Sanitaire, 2002 (HIV/AIDS Surveillance in Europe, No. 37).

53. Rieder HL, Watson JM, Raviglione MC, et al. Surveillance of tuberculosis in Europe. Recommendations of a Working Group of the World Health Organization and the European region of the International Union Against Tuberculosis and Lung Disease for uniform reporting on tuberculosis cases. Eur Respir J 1996; 9: 1097-1104.

54. Veen J, Raviglione M, Rieder HL, et al. Standardized tuberculosis treatment outcome monitoring in Europe. Recommendations of a Working Group of the World Health Organization and the European region of the International Union Against Tuberculosis and Lung Disease for uniform reporting by cohort analysis of treatment outcome in tuberculosis patients. Eur Respir $J$ 1998; 12: 505-510.

55. Schwoebel V, Lambregts-van Weezenbeek CS, Moro ML, et al. Standardization of antituberculosis drug resistance surveillance in Europe. Recommendations of a World Health Organization and the International Union Against Lung Disease Working Group. Eur Respir J 2000; 16: 364-371.

56. Guidelines for HIV surveillance among tuberculosis patients. 2nd Edn. Draft presented at the 3rd Global TB/HIV Working Group Meeting, Montreux, Switzerland, 4-6 June 2003. Geneva, World Health Organization, 2003.

57. Uplekar MW, Rangan S, Weiss MG, Ogden J, Borgdorff MW, Hudelson P. Attention to gender issues in tuberculosis control. Int J Tuberc Lung Dis 2001; 5: 220-224.

58. Lexicon of alcohol and drug terms. Geneva, World Health Organization, 1995. whqlibdoc.who.int/publications/ 9241544686.pdf. Date accessed: 25 September 2003. 